\title{
Lenguaje audiovisual en la cultura digital: Enchufe.tv y las estrategias de fidelización
}

Audiovisual language in digital culture:

Enchufe.tv and engagement strategies.

(D) Diana Chamorro Flores

di988@hotmail.com

Universidad Andina Simón Bolívar (Quito, Ecuador)

https://orcid.org/0000-0001-7706-4019

DOI https://doi.org/10.32719/26312514.2020.3.6

\section{Resumen}

Las organizaciones han encontrado en las redes sociales un canal para llegar a su público objetivo. Sin embargo, no todas cuentan con una estrategia de comunicación eficiente. En el presente estudio, se escogió a Enchufe.tv para analizar los contenidos que publica en su Like page, con el fin de entender si la información que se difunde crea engagement y está logrando fidelizar a sus usuarios. Para esto, se indagó en los contenidos textuales y visuales de las publicaciones durante 2015 y se llevó a cabo un estudio de la interactividad. Se aplicó también una encuesta y entrevista para conocer en detalle qué es lo que piensan los seguidores sobre los contenidos y el desempeño de la Like page.

\begin{abstract}
Organizations have found a way to reach their target audience through social media. However, not all of them have been able to implement an effective communication strategy. For a case-study, Enchufe.tv was chosen to analyze the content on its 'Like' page and determine whether the disseminated information is creating engagement and gaining loyalty of the users. To achieve this, textual and visual contents of the posts that were published during 2015 were investigated and a study of interactivity was carried out. Surveys and interviews were also carried out to get a feedback from their fans on the content and performace of the 'Like' page.
\end{abstract}

\section{Palabras clave $\cdot$ Keywords}

Compromiso; like page; redes sociales.

Engagement; like page; social media. 


\section{Introducción}

Enchufe.tv es un programa ecuatoriano cuya difusión se realiza a través de la plataforma digital YouTube. Este programa ha logrado posicionarse rápidamente en el mercado nacional e internacional gracias a la calidad de producción de sus videos, así como por la originalidad de sus contenidos, enlazados al barroco ecuatoriano. El rápido crecimiento de Enchufe.tv así como el desarrollo de la comunicación en los medios digitales, ha hecho que sea necesario disponer de los contenidos de la serie web en las redes sociales.

En el contexto actual, es importante analizar la comunicación que se realiza en estas redes, pues se han convertido en espacios de intercambio donde la opinión pública puede manifestarse de manera libre, espontánea, sin limitaciones y sin represalias. Además, estas favorecen el reconocimiento por conformidad, pues una de las necesidades de los humanos es sentirse aprobado y ser parte de un grupo o comunidad. De acuerdo con Crovi, M. López y R. López $(2019,14)$, "red" viene del latín "rete", que quiere decir "cuerdas separadas". En las redes, se permite el intercambio de información a través de varios canales (15). Entonces, las redes sociales serían los espacios en los se unen y retienen las relaciones que, en el campo no virtual, están separadas.

Las redes sociales se puntualizan como un "conjunto de lazos que vinculan a los miembros del sistema social a través, y más allá, de las categorías sociales y los grupos cerrados" (41). Carlos Lozares (citado en Crovi, M. Líopez y R. López 2019, 42) considera que una red social es un "conjunto bien definido de actores -individuos, grupos, organizaciones, comunidades [...]-, que están vinculados unos a otros a través de una o un conjunto de relaciones sociales". Estos autores coinciden en que, en las redes sociales, existen amistades o lazos entre sujetos. Se busca unir relaciones y establecer puntos de conexión entre los usuarios.

Las comunidades digitales facilitan "la agrupación 'virtual' — a distancia y, en principio, anónima - de personas por sus afinidades de intereses y valores, la comunicación online favorecería que, en un mundo fuertemente privatizado e individualizado, se regenerara la sociabilidad, al promover el establecimiento de lazos de apoyo mutuo y amistad, capaces de ampliarse, después, a la comunicación verdaderamente interpersonal: la que se produce face to face" (García 2002, 98). Hoy, la vida se desenvuelve en línea. Todo sucede en el mundo digital.

Las redes sociales constituyen un área de estudio de gran importancia para la comunicación estratégica, tanto por su protagonismo contemporáneo como cuando son apropiadas como espacio para la realización de programas institucionales. Actualmente se vive en una jungla informativa en la que resulta imposible desenvolvernos sin el uso de la tecnología. Sin conectividad, la vida de los seres humanos no puede desarrollarse plenamente.

Nuestras costumbres, creencias, ideologías, entre otros, han cambiado radicalmente desde que el mundo empezó a crear comunidades virtuales. Esto ha hecho que nuestro 
concepto de sociedad, comunidad, ciudadanía y nuestra propia autoconcepción se modifique y se adapte a la transformación de la masa (Whitaker 1999, 11).

Las organizaciones han encontrado en las redes sociales una nueva manera de llegar a su público. De acuerdo con Martínez, Sánchez y Parra $(2015,43)$, "en el siglo XXI las empresas son las personas y el poder ahora es individual, a través de las redes sociales. Y las redes sociales son de las personas". Es decir, las empresas ahora no solo las manejan quienes las administran, sino también el usuario, el público, el consumidor, etc. cumplen un rol trascendental en ella. La audiencia tiene un gran poder gracias a las redes sociales, pues pueden ser escuchadas más allá de las fronteras físicas y comunicacionales a las que se estaba acostumbrado.

Para Marquina $(2013,16)$, existen tres tipos de espacios en Facebook: perfil, página y grupo. En esta investigación, se va a analizar la Like page, la cual está orientada a marcas u organizaciones. Una Like page, a diferencia de un perfil, puede ser administrada por varias personas y los datos de la empresa están presentes de manera pública. Este tipo de página permite establecer un nexo con los usuarios, en el que se difunden productos o servicios. En ellas, los usuarios pueden comunicarse directamente con la marca o empresa. Otro punto significativo de estas páginas es que se puede compartir todo tipo de contenido. Esta es una ventaja para las empresas o marcas, pues permite la viralización de los contenidos, logrando un mayor alcance de la marca. Según esta definición, este tipo de páginas permite a las empresas o instituciones tener una ventana abierta hacia sus potenciales compradores. Ayuda a que los usuarios puedan sentirse escuchados por las empresas. Ese fue el caso de Enchufe.tv, que encontró en las redes sociales un canal de comunicación directa con su comunidad. Sin embargo, la administración de una Like page implica que se generen contenidos atrayentes, creando engagement y fidelización de los miembros de la comunidad.

\section{Metodología}

Para esta investigación, se ha seguido una metodología de carácter mixto, cualitativo y cuantitativo, no experimental. Por su alcance, la presente investigación es principalmente explicativa, pero también se vale de la investigación descriptiva.

El universo de estudio de esta investigación se limita a las publicaciones realizadas en Facebook durante 2015 y a los datos estadísticos obtenidos en 2016. En 2015, se analizaron los contenidos publicados en relación con los videos con un mayor porcentaje de visitas durante ese año, mientras que 2016 sirvió con un año de referencia para realizar una comparación en la forma de participación de los usuarios, debido a los avances tecnológicos en Facebook que han permitido una mayor interactividad en las Like page.

Es transcendental subrayar que la manera de participación en 2016 es distinta a la de 2015 por los cambios en la interface y formas de interacción que se dieron en esta 
red social. Además, servirá como una fuente de obtención de datos estadísticos, ya que la plataforma no almacena datos del desempeño de una determinada Like page de años pasados.

En total, existen 621 contenidos publicados durante 2015. Se escogió este año para realizar la investigación, ya que las publicaciones de Enchufe.tv durante 2014 son mínimas, con contenidos esporádicos.

Para 2016, Facebook lanza nuevas opciones para la difusión de contenidos en la red social. Este año se pueden difundir imágenes con movimiento, en formato gif, y se pueden publicar también videos. Además, es posible hacer transmisiones en vivo. Otra novedad es la posibilidad que tienen los usuarios de escoger entre nuevas "emociones" (emoticones) que les dan una mayor libertad para demostrar sus sentimientos ante una publicación determinada.

La interactividad de los contenidos fue evaluada mediante parámetros e indicadores que fueron aplicados a los 19 publicaciones de los videos más vistos durante 2015.

Tabla 1: Videos más visualizados durante 2015

\begin{tabular}{|c|c|c|c|}
\hline Video & Enlace & Fecha & Visualizaciones \\
\hline $\begin{array}{l}\text { Viendo } \\
\text { como chica } \\
\text { menstruando }\end{array}$ & $\begin{array}{l}\text { https://www. } \\
\text { YouTube.com/ } \\
\text { watch?v=alKO4IRglyQ }\end{array}$ & $\begin{array}{l}25 \text { de enero de } \\
2015\end{array}$ & $\begin{array}{l}24.074 .717 \\
\text { visualizaciones }\end{array}$ \\
\hline $\begin{array}{l}\text { Qu3 h3ch0 v3rg4 } \\
\text { mis } 15\end{array}$ & $\begin{array}{l}\text { https://www. } \\
\text { YouTube.com/ } \\
\text { watch?v=YeaUwwzwfZk }\end{array}$ & $\begin{array}{l}15 \text { de marzo de } \\
2015\end{array}$ & $\begin{array}{l}19.658 .720 \\
\text { visualizaciones }\end{array}$ \\
\hline Fotos familiares & $\begin{array}{l}\text { https://www.YouTube. } \\
\text { com/watch?v=C- } \\
\underline{\text { sXNIsRxI4 }}\end{array}$ & $\begin{array}{l}6 \text { de abril de } \\
2015\end{array}$ & $\begin{array}{l}\text { 13.947.917 } \\
\text { visualizaciones }\end{array}$ \\
\hline $\begin{array}{l}\text { ¿Quieres ser mi } \\
\text { novia? }\end{array}$ & $\begin{array}{l}\text { https://www. } \\
\text { YouTube.com/ } \\
\text { watch?v=nzuSF9J7Thk }\end{array}$ & $\begin{array}{l}13 \text { de abril de } \\
2015\end{array}$ & $\begin{array}{l}18.569 .069 \\
\text { visualizaciones }\end{array}$ \\
\hline $\begin{array}{l}\text { Qu3 h3ch0 v3rg4 } \\
\text { tener una amiga } \\
\text { rica }\end{array}$ & $\begin{array}{l}\frac{\text { https://www. }}{\text { YouTube.com/ }} \\
\text { watch?v=xqGZU4036a0 }\end{array}$ & $\begin{array}{l}7 \text { de junio de } \\
2015\end{array}$ & $\begin{array}{l}16.543 .651 \\
\text { visualizaciones }\end{array}$ \\
\hline $\begin{array}{l}\text { Viendo como } \\
\text { novia celosa }\end{array}$ & $\begin{array}{l}\text { https://www. } \\
\text { YouTube.com/ } \\
\text { watch?v=Sfbsa66MPUk }\end{array}$ & $\begin{array}{l}31 \text { de agosto de } \\
2015\end{array}$ & 8.459 .430 visualizaciones \\
\hline
\end{tabular}

Fuente: Like page Enchufe.tv

Elaboración Diana Chamorro

Se adoptó la práctica de medición de interacciones empleada por Facebook, basada en las distintas acciones sociales en la red social. En Facebook se puede contabilizar la 
cantidad de me gusta, comentarios y compartidos. Para finalizar, se realizaron 50 encuestas a los fans de Enchufe.tv con el fin de conocer su apreciación sobre la serie web, los intereses que tienen en la serie, los usos y frecuencia con que miran los contenidos de Enchufe.tv en Facebook, entre otras preguntas. Las entrevistas, en cambio, permitieron tener una apreciación un tanto más profunda y detallada sobre los temas antes mencionados.

\subsection{Descripción de la muestra}

Para conocer si en la Like page de Enchufe.tv se trabaja por la fidelización de los seguidores, se realizaron 50 encuestas a usuarios ecuatorianos de la serie, gran parte de los que son adolescentes. No obstante, también se realizó la encuesta a personas cuyas edades oscilan entre los 30 y 50 años para tener un conocimiento un poco más amplio. El $64 \%$ del universo analizado es de sexo masculino, mientras que el $36 \%$ son mujeres. Los ciudadanos a los que se encuestó se encuentran en las ciudades de Quito, Guayaquil, Manta y otras ciudades de Ecuador que, por cuestiones de extensión de la encuesta, no se especificaron.

El nivel de estudios de la mitad de los encuestados es superior, mientras que el $26 \%$ están en la secundaria y un $16 \%$ de esta muestra ha realizado al menos una publicación en la Like page. Si bien el universo de la comunidad de Enchufe.tv es muy amplio, en este estudio se escogió a 50 personas para aplicar la encuesta, pues son usuarios activos en redes sociales, seguidores de larga trayectoria de Enchufe.tv tanto en YouTube como en Facebook, con un carácter crítico en la selección de contenidos digitales y ecuatorianos inmersos en la idiosincrasia nacional. Estos usuarios constituyen una muestra del universo de estudio.

\section{Resultados}

\subsection{Texto, imágenes y símbolos usados}

Estos resultados se obtuvieron a partir del análisis profundo de los contenidos de Enchufe.tv. Es decir, de la decodificación de los elementos textuales y gráficos. Sobre la base de los sketches más vistos durante 2015, se identificaron 20 publicaciones en Facebook. Para los elementos textuales, se analizaron los siguientes aspectos: palabras usadas en las publicaciones y uso de los enlaces, mientras que, para las imágenes y elementos visuales, se estudiaron los elementos que las conforman, posiciones y colores empleados.

Tras el análisis, se encontró que, en estos elementos comunicacionales, se usan situaciones y experiencias que el target de la serie web ha tenido o experimenta. Es decir, se recurren a las rutinas que tienen los ecuatorianos en su diario vivir o que son comunes en un momento de vida específico.

En varios de los contenidos presentados se refuerza el estereotipo de lo bello y lo grotesco para generar empatía en el consumidor. Se pudo apreciar que no existe una in- 
tención de respetar las normas de ortografía. Los signos de puntuación y las palabras se usan como si se estuviera hablando de manera coloquial. Esta puede ser la razón por la que las publicaciones generan tanto engagement entre los seguidores y les motiva a compartir las imágenes.

Según Acaso $(2006,37)$, la tecnología ha cambiado la manera en que las personas se comunican, pues el discurso oral se ha visto enriquecido con el lenguaje icónico y el audiovisual, especialmente en las redes sociales. Se debe mencionar que, aunque la postura de unos autores es señalar que el lenguaje se ha visto afectado por las redes sociales, otros consideran que la comunicación ha tenido un gran desarrollo gracias a ellas.

También se puede evidenciar que los textos que se encuentran aparte de la fotografía no transmiten mucha información. De hecho, este espacio se ha convertido en el sitio para colocar el enlace del video y escribir una frase llamativa que genere interés y haga que los seguidores de Enchufe.tv le den clic para acceder.

Se utiliza el mínimo de recursos textuales para dar mayor importancia al recurso visual, aumentando así el engagement de los contenidos de la serie web. En el caso de Enchufe.tv, se hace evidente que la gramática y la escritura se ven afectados por la forma en que se emplea el lenguaje. Sin embargo, a los seguidores de la serie parece llamarles la atención el uso alterado de las palabras y su escritura. Incluso, se cree que se sienten identificados, porque algunos de los comentarios que hacen los fans tienen una escritura similar a la que se tiene en las publicaciones de Enchufe.tv.

Otro hallazgo que se obtuvo en esta investigación fue que el uso de palabras en las publicaciones de Facebook es limitado. Es decir, se les da un mayor valor a los elementos gráficos que a las palabras, lo que haría deducir que se intenta transmitir un mensaje claro, conciso y que genere engagement con una sola imagen. De manera que las palabras quedan relegadas a un segundo plano y se usan cuando es estrictamente necesario.

El número de palabras promedio por publicación es de 4,25, con un mínimo de 1 y un máximo de 11 palabras. Se tiende a utilizar los dos puntos para presentar el nombre del video al que se está promocionando. Además, se coloca el enlace completo de YouTube en todas las publicaciones. Sobre el tema del dinamismo en la redacción, se puede exponer que el $73 \%$ de los titulares (en la parte del texto) de las publicaciones analizadas cuenta con un contenido fuerte, que llame la atención.

Por contenido fuerte se entiende aquella información relevante para el usuario que genere atracción al leerlo. Es esa información que un usuario no puede descartar o ignorar. En cambio, el texto usado en el arte de la publicación tiende a ser menos fuerte. De hecho, únicamente la mitad $(52,63 \%)$ de los textos en los artes gráficos son atrayentes. Se evidencia con esta cifra que se da mayor importancia al uso de memes o artes gráficos.

El 68,42\% de los contenidos difundidos en la Like page cuentan con una imagen y un texto que los acompaña, aunque se debe reconocer que todas las publicaciones están 
acompañadas por el enlace del video que se promociona. En Facebook y en gran parte de las redes sociales, el uso de las imágenes es fundamental. El texto ha pasado a segundo plano, incluso muchas veces se puede prescindir de él si la imagen es completamente descriptiva. El uso de imágenes o fotografías es fundamental en esta Like page. Las palabras, en cambio, no lo son, ya que se da un mayor énfasis a los elementos visuales.

Cada imagen se acompaña de un enlace que debería garantizar el ingreso de usuarios en el video que se promociona con cada fotografía en la Like page. Se podría decir que el uso de estos elementos favorece la interacción de los usuarios, quienes participan y crean contenidos propios, alimentando así los contenidos existentes en la Like page de la serie web.

En el estudio realizado, se encontró que el porcentaje de uso de fotografías en la Like page es del $100 \%$. El uso de artes especiales en las fotografías en Enchufe.tv no es muy habitual. De hecho, casi el $50 \%$ de ellas tiene un diseño específico.

En cuanto a los signos usados en la comunicación en Facebook, se encontró que la tendencia es usarlos en la imagen y no tanto en el texto de la publicación; es decir, en la parte destinada a escribir una descripción del contenido publicado.

El porcentaje de uso de palabras empleadas en la gestión de la comunicación en cada publicación alcanzó el 84 \%. En promedio, se usan cuatro palabras por publicación. En este sentido, se entiende que Enchufe.tv hace un uso del lenguaje textual directo y concreto y brindándole una mayor importancia al lenguaje visual con el uso de memes. De ahí que se sostenga que hay un mayor empleo del recurso gráfico que el textual

\subsection{Análisis de interactividad}

Del análisis que se efectuó de la interactividad en la Like page de Enchufe.tv, se obtuvieron los siguientes resultados a través del registro de información en tablas de medición de datos: los videos más comentados y que registran un mayor índice de interactividad son aquellos relacionados con hechos vergonzosos vinculados con mujeres.

Se debe mencionar que los temas de los videos analizados en este trabajo de investigación tienen que ver de una u otra forma con el sexo femenino. En algunos sketches, la mujer actúa como personaje protagónico, mientras que, en otros, es el elemento sobre el cual se guía el protagonista. La mujer, muchas veces, tiende a ser un objeto de burla o un obstáculo para que el sexo masculino logre sus objetivos.

Tomando en consideración esto, se puede mencionar que, desde la antigüedad, la sociedad se ha ido construyendo desde lo masculino. Los hombres han sido quienes ocupan los mejores cargos, los que mejores salarios obtienen, los que tienen el poder y sobre la base de quienes el mundo funciona. La mujer ha sido considerada como un ser subalterno; como el otro; el ser inferior. 
Según Barquet (2002, 9), la mujer es considerada como un objeto y sujeto central de subordinación. El género puede ser considerado desde una perspectiva biológica y desde una construcción cultural. Esto es lo que sucede muchas veces con los contenidos digitales de Enchufe.tv. La mujer es el alterno del hombre. Además, se la usa, en algunos casos, para exhibir su figura en las imágenes de las publicaciones.

Los usuarios tienen una acción participativa claramente manifestada ante los contenidos presentados en la Like page de Enchufe.tv, pues la totalidad de las publicaciones analizadas recibieron comentarios, que incluyen memes en un $78 \%$ de las publicaciones. Además, todos fueron compartidos y recibieron likes. Otro recurso que se usa en todos los contenidos publicados es la difusión del enlace de YouTube del video al que se hace referencia en cada imagen.

No existe respuesta por parte de Enchufe.tv a los comentarios que realizan los usuarios en la Like page y tampoco se realizan concursos o se usa otro elemento que incentive aún más la participación. Es relevante recalcar que la participación en redes sociales se refiere a cualquier tipo de interacción que se registre o manifieste entre los seguidores.

En otros términos, la participación es un tipo de interacción. Se podría entender a esta última como un macro, como algo grande que abarca todo el comportamiento, reacción y elementos o herramientas usadas para crear engagement e interacción, mientras que la participación es solo un segmento que forma parte de ese todo conocido como interacción. La interactividad depende de la acogida que tiene el mensaje enviado y de lo relevante que este le parezca a la audiencia para que registre su participación, comentarios, compartidos, etc. Según los datos arrojados en las tablas de interacción elaboradas en este trabajo de investigación, existen 1339999 usuarios que dieron clic en las publicaciones difundidas en la fan page.

Asimismo, existe un total de 11852 comentarios realizados por los usuarios en las publicaciones analizadas en este trabajo de investigación. Aunque el porcentaje de compartidos es menor que los datos mencionados anteriormente (8240), se puede advertir que existe una intención por difundir las publicaciones de la serie web para que otros usuarios también puedan verlos e interactuar con ellos.

El segundo requisito que deben cumplir los seguidores es el deseo por adquirir material relacionado con el objeto de devoción. En relación con esto, se argumenta que quienes han manifestado un deseo por adquirir este material son aquellos que le han puesto "me gusta" a la Like page de la serie web. Es decir, existen 8790128 personas que han manifestado este interés por obtener en su muro de la red social información sobre Enchufe.tv.

El 68,42 \% de los contenidos difundidos en la Like page cuentan con una imagen y un texto que los acompaña, aunque se debe reconocer que todas las publicaciones están acompañadas por el enlace del video que se promociona. En este punto, se podría afinar que el texto no es una prioridad en los contenidos de la fan page de la serie web, a dife- 
rencia de lo que sucede con los sketches, donde el texto o guion constituiría la base de la comedia y originalidad de Enchufe.tv.

\subsubsection{Encuesta}

Del análisis que se hizo de la fidelización en la Like page de Enchufe.tv se obtuvieron los siguientes resultados: Los fans de la serie son seguidores por un período superior a los dos años y su consumo de videos es semanal (gráfico 1) y no diario como se esperaría mediante la campaña de enlaces usada en Facebook.

Gráfico 1: Frecuencia con la que los seguidores miran Enchufe.tv

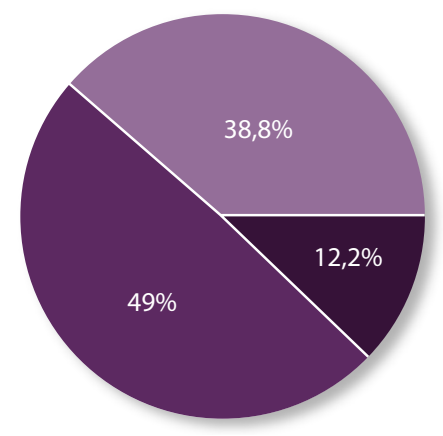

$$
\begin{aligned}
& \text { - Diariamente } \\
& \text { - Semanalmente } \\
& \text { - Una vez al mes }
\end{aligned}
$$

Fuente: Like page Enchufe.tv Elaboración propia

El 84\% de las personas que fueron encuestadas siguen a la serie en su Like page. Sin embargo, existe un $16 \%$ que no los sigue en esta red social. Esto daría a entender que hay una cantidad de usuarios que desconoce la presencia de Enchufe.tv en las redes sociales. Quienes siguen a la serie web en Facebook lo hacen hace más de un año, según indican los resultados del sondeo. Un 24\% manifestó seguirlos hace un año.

Otro hallazgo es que Facebook no tiene un impacto significativo en las visualizaciones de los sketches en YouTube: el 82\% de los encuestados dijo que mira los sketches directamente desde YouTube, apenas el 8\% mira los videos por Facebook.

Es importante comparar esta cifra con el 6\% de usuarios que mira Enchufe.tv en Ecuavisa. Los usuarios, además, indicaron que otras redes en las que siguen a Enchufe.tv son Snapchat y Twitter. Cabe destacar que el 14\% de los seguidores dijeron que no siguen a la serie en ninguna otra red (gráfico 2). 
Gráfico 2: Plataforma en que los usuarios observan los sketches de Enchufe.tv

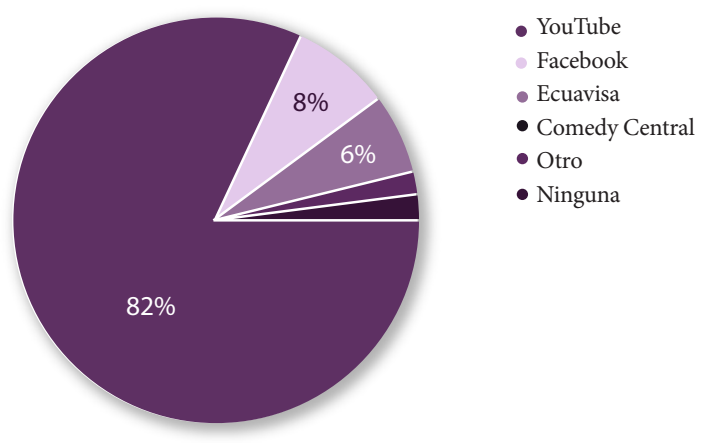

Fuente: Like page Enchufe.tv Elaboración propia

Se preguntó a los seguidores si ellos dan clic a los enlaces que se colocan en las publicaciones de Facebook. A esto, la mitad de los encuestados dijo que sí y la otra dijo que no.

Entonces, se puede creer que la estrategia está siendo eficiente en un $50 \%$. Las visitas en la Like page, según indicó el $52 \%$ de los usuarios, son ocasionales. Un $22 \%$ dijo que sigue a la serie web en Facebook, pero no ingresa a la Like page. El 20 \% dijo que lo hace regularmente y apenas el $6 \%$ indicó que lo hace constantemente. Ese $6 \%$ ingresa a la Like page por su propio interés.

Otros ingresan a la página por referencia de una publicación compartida y un 10 \% lo hace porque vio un anuncio de Enchufe.tv en la red social. Lo que más les llama la atención en los sketches a los usuarios son los personaje. En segundo lugar, se encontró la trama e historia.

\subsubsection{Entrevista}

Del análisis de la fidelización y engagement, sobre la base de las entrevistas realizadas a cinco seguidores de la Like page, mujeres y hombres ecuatorianos de entre 20 y 50 años, se obtuvieron los siguientes resultados: no existe una fidelidad real hacia la serie, ya que la preferencia de los seguidores hacia Enchufe.tv se da por cuestiones de "moda", como manifestaron los encuestados. Gracias a las entrevistas aplicadas de manera personal a los fans, se dedujo que la falta de fidelización hacia la serie web en Facebook puede deberse a temas de tendencia ocasional.

Los usuarios expresaron que siguen a la serie web por su reconocimiento nacional e internacional, así como también por sus temas novedosos y cómicos, aunque, en la ac- 
tualidad, sus guiones ya no sean tan seductores como eran en sus primeros capítulos. Los seguidores dijeron que los videos antiguos son más entretenidos, pues los sketches nuevos repiten la secuencia narrativa y presenta lo que ya se ha visto en videos pasados. Aunque los encuestados expusieron que Enchufe.tv ha perdido gracia, cabe destacar que la serie es considerada un referente de diversión, porque los contenidos que se publican tratan sobre asuntos bochornosos, tabúes o cotidianos que hacen que las personas se tomen con más calma estos temas e incluso se burlen de los mismos.

Pasando al tema de las redes sociales, los seguidores manifestaron no tener un compromiso que los haga sentirse parte de Enchufe.tv. Todos señalaron sentirse como uno más de los fans de la serie web, pero ninguno manifestó un sentimiento de extremo apego. Incluso, algunos dijeron que no sienten que lo que comunica Enchufe.tv en su Like page ayude a que ellos se sientan más cercanos a la serie. Lo que existe es un seguimiento de las actividades de Enchufe.tv, pero no se evidencia fidelización.

Ninguno de los encuestados recomendó a otros de sus amigos seguir a la serie en redes porque dan por entendido que se trata de una serie famosa que todas las personas deberían seguir. Además, destacaron que no ponen mucha atención en los contenidos que publica la serie en su Like page. De hecho, muy pocos de los entrevistados ingresan exclusivamente a la Like page de la serie, mientras que otros solo reciben las noticias que se encuentran en su muro. Se debe recordar que las noticias que aparecen en los muros se dan de manera aleatoria y que no llega a todos los admiradores. Este podría ser considerado como el mayor problema para la falta de fidelización en la Like page. El engagement no es suficiente para hacer que los seguidores se mantengan pendientes de los contenidos.

Los contenidos en redes sociales necesitan tener un valor o beneficio para la vida de los usuarios y para su comunidad para lograr que estos sean compartidos.

\section{Discusión}

En la Like page de Enchufe.tv, existe un intento por crear empatía con los seguidores, ya que se usan elementos, situaciones y experiencias que el target de la serie web ha tenido o pudo haber experimentado alguna vez en su vida. Se busca que el usuario asimile los contenidos y vincule directamente comedia y diversión con la marca, el nombre y el logo de la serie web. Tras analizar los resultados, se puede entender que los community manager de Enchufe.tv usan la Like page de la serie web para crear fidelización con los usuarios que provienen de YouTube o con los usuarios que ya son seguidores en Facebook. Esto se debe a que los contenidos que se presentan no permiten que cualquier persona los entienda. Es decir, un usuario que no ha visto ni conoce Enchufe.tv difícilmente entenderá lo que se comunica en las publicaciones de la serie web. Quienes manejan las redes sociales de esta serie web usan Facebook para fidelizar el público ya existente en sus redes y no para ampliar su audiencia. 
El lenguaje que Enchufe.tv maneja en Facebook está orientado a una comunidad que ha manifestado sentir agrado por el sketch, por lo que podría resultar más accesible llegar a ellos con contenido que se tiene conocimiento que es de su deleite. En YouTube, el campo de usuarios es mayor y puede resultar más complejo lograr que quienes no conocen el canal de la serie ecuatoriana puedan sentir agrado y empatía hacia los contenidos presentados. En otras palabras, si bien en YouTube también se forman comunidades, el campo de distribución en esta red es más amplio que el de Facebook. Por lo que los contenidos deben contar con un lenguaje que sea accesible y fácil de asimilar para todos los usuarios.

Enchufe.tv genera confianza entre sus seguidores y eso crea fidelidad. El engagement se consigue mediante el uso de fotografías que funden identidad o empatía con algún hecho o circunstancias que haya tenido el usuario, aunque también se recurre a los estereotipos. Además, se permite al fan tener un proceso de completación que asegura que el mensaje enviado en cada publicación se adapte a lo que el usuario quiere y espera ver.

Los símbolos e imágenes usados en las publicaciones de la Like page de Enchufe. tv responden a los estereotipos establecidos por la sociedad. Esto hace que los usuarios se sientan identificados con lo que ven. Por eso, los seguidores tienden a replicar las imágenes de la serie web, ya sea difundiendo o creando contenido propio que es compartido en los comentarios de cada publicación.

En este punto, se podría afinar que el texto no es una prioridad en los contenidos de la Like page de la serie web, a diferencia de lo que sucede con los sketches, en donde el texto o guion constituiría la base de la comedia y originalidad de Enchufe.tv. Los contenidos publicados con imagen y texto son suficientes para crear participación. Con eso se creería que los fans sienten la necesidad de ser escuchados y de expresar sus puntos de vista.

Enchufe.tv ha adquirido fama porque los sketches muestran asuntos que muchas veces no se toman en cuenta o se los evita en conversaciones sociales, pero en los videos de la serie web se tratan estos temas de manera jocosa, por lo que resulta más fácil digerirlos o aceptarlos. El proceso de identificación que manifestaron los usuarios se debe al reconocimiento que existe con las locaciones, vocabulario y, aunque en un porcentaje menor, en la trama o situaciones que se presentan. Los seguidores coincidieron en que su agrado por la serie web se debe a lo cómico. Se trataría de un punto en común, que hace que todas las personas que miran los sketches se asemejen en gustos, preferencias, etc.

Los usuarios no cuentan con una razón fuerte que los motive a crear un compromiso sincero con la Like page y con la marca en sí. Todos los encuestados dijeron sentirse como uno más de los fans, pero ninguno manifestó un sentimiento de excesiva simpatía. Incluso, algunos dijeron que no sienten que lo que comunica Enchufe.tv en su perfil ayude a que ellos se sientan más cercanos a la serie. Por eso, se puede argüir que Enchufe. tv se está quedando únicamente en una atracción temporal, que no genera compromiso con los 
fans. Es decir, la estrategia actual en Facebook está generando engagement, pero no se ha logrado fidelizar a los seguidores. Si no existe fidelización, la comunidad de la Like page no crecerá e incluso podría perderse los seguidores que se han logrado.

\section{Conclusiones}

El objetivo de esta investigación es entender en qué medida los textos, imágenes y símbolos difundidos en la Like page de Enchufe.tv contribuyen a aumentar el engagement, logrando así fidelizar a los seguidores en esta red social. Para esto, se llevó a cabo el análisis de los textos e imágenes de la serie web en su Like page, así como también se realizó un estudio de la interacción que generan los contenidos mediante el uso de tablas de medición y, finalmente, para realizar un análisis cualitativo, se llevó a cabo entrevistas y encuestas para profundizar el estudio del engagement y fidelización.

En la actualidad, existen muchas versiones de cómo funciona el engagement en las redes sociales; sin embargo, no existe un consenso de cómo trabaja esta métrica digital. En los últimos años, se ha pasado de objetivos "sentimentales" a objetivos de negocios, que están enfocados únicamente en la parte comercial. En el caso de Enchufe.tv, Touché Films ha convertido a esta serie web en un producto o una estrategia de marketing de contenido. En otras palabras, a través de esta estrategia, la productora ha podido vender a grandes empresas ecuatorianas sus contenidos digitales. Se puede evidenciar que Enchufe.tv ha trabajado para probar al medio audiovisual ecuatoriano su capacidad creativa y calidad de producción. Posiblemente su principal fin no era el engagement, sino mostrar sus capacidades audiovisuales. Sin embargo, en este trabajo de investigación se puede apreciar que el engagement es su principal objetivo en su Like page.

Partiendo de la existencia de comunidades digitales y nuevas formas de comunicación e interacción, las conclusiones que se obtuvieron en esta investigación tienen un valor experimental, basando en el estudio de contenido aplicado a las publicaciones de los videos más vistos durante 2015, así como también se ha demostrado por medio de una encuesta y entrevistas aplicadas a seguidores de Enchufe.tv.

El engagement que se refiere a todo lo "relativo al tipo de interactuación que el usuario lleva a cabo, basado en el ratio de los usuarios referenciados por el perfil y los usuarios que lo referencian" (Nicolás Ojeda y Grandío 2012, 53). Al finalizar esta investigación, se concluyó que un contenido que cree un engagement constante generará fidelización, pues el usuario tendrá una alimentación constante de las acciones de Enchufe.tv, se sentirá parte de la serie, llenará sus necesidades que, en este caso, estarían relacionadas con la diversión, se sentiría escuchado cuando la marca responde a sus inquietudes, entre otros. En el caso de la serie web, algunas de las publicaciones generan engagement, pero hay otros cuyo mensaje no es claro y el usuario tiende a perder interés en el contenido que se le presenta. 
Los contenidos digitales de Enchufe.tv buscan atraer a espectadores y brindarles contenidos que generen fidelidad. Se puede apreciar que existen muchos elementos que se repiten constantemente. Se trata de contenidos que generan empatía en la mayoría de los seguidores y que, por esta razón, se genera una continua accesibilidad a ellos. En este sentido, se puede sugerir que es necesario establecer una estrategia de comunicación que guíe el mensaje que se quiere transmitir en cada publicación, con el fin de lograr el objetivo deseado. En las publicaciones de Enchufe.tv, existe contenido y comunidad. No obstante, la falta de contexto en la publicación no permite lograr una buena conexión con los seguidores y esto no motiva a la fidelización de los mismos.

En el tema del análisis del texto e imágenes usadas en la Like page de Enchufe.tv, se encontró lo siguiente: primero, existen recursos de machismo y estereotipos que crean lazos de unión con los usuarios, pues de una u otra manera se sienten identificados. Este es un argumento que coincide con el planteado por Montaño. Según esta autora, los videos de Enchufe.tv se basan constantemente sus "parodias, burlas y guiones en un discurso machista, androcéntrico y adultocéntrico en la que se desvirtúa la imagen de la mujer, a tal punto que llega a ridiculizarla como dominante y traicionera, mala amiga y en algunos casos como la chica rica inalcanzable" (Montaño 2015, 104). El mayor recurso que se usa es el de la mujer, la cual es vista desde su rol como madre, hija, novia, así como también desde la perspectiva de la maldad, cruel y hasta como un obstáculo.

Varios seguidores de la serie web dijeron que siguen a Enchufe.tv porque les parece un programa excelente, pese a que están conscientes de que se recurre a los estereotipos para crear contenidos divertidos basados en lo cotidiano. Los personajes persiguen fines pragmáticos, que se ven obstaculizados permanentemente por otros factores. Ese sería el camino del éxito en las tramas de la serie web. Los contenidos de Enchufe.tv en su Like page presentan vínculos culturales, que son utilizados como insights para generar engagement en su público objetivo, y estos a su vez afirman estereotipos sociales. Los insights se han convertido en la herramienta de mayor uso en los contenidos digitales y visuales de la serie web, pues el usuario se siente identificado y se crea en él la necesidad de compartir el contenido. Un usuario que crea afinidad con un contenido querrá compartirlo con sus allegados y así es como estos contenidos se vuelven virales.

Segundo, en esta investigación, se encontró que los usuarios de la comunidad de Enchufe.tv usan memes a modo de comentarios. De acuerdo con Delia Rodríguez (2000, 23), "los memes son ideas que saltan de mente en mente. Independientes de nosotros, las ideas contagiosas pueden venir de cualquier época y lugar y evolucionan sin nuestro permiso". El uso de memes en los comentarios puede entenderse como una forma de evolución de los lenguajes en la cultura digital, en este caso como un mecanismo de identificación que genera engagement.

Tercero, en cuanto a las imágenes también se puede concluir que Enchufe.tv se vale del proceso de completación que realizan los seres humanos para entender un mensaje 
determinado. En otros términos, la serie web envía un mensaje que podría ser considerado como neutro para que sea el seguidor quien complete la comunicación y conciba lo que quiera entender en relación con su contexto social y educación. Además, se encontró que en las imágenes de las publicaciones se recurre a la belleza de sus actores para generar engagement en sus videos y en los contenidos de sus redes sociales. En cuanto a los textos usados en las publicaciones, se descubrió que los signos de puntuación y las palabras se usan como si se estuviera hablando de manera coloquial y se emplean de manera muy limitada. Se concluye que esta puede ser la razón por la que las publicaciones generan tanto engagement entre los seguidores y les motiva a compartir las imágenes. Encuentran en las imágenes un valor que el texto no requiere brindar. Se busca que el usuario asimile los contenidos y se vincule directamente la comedia y diversión con la marca, el nombre y el logo de la serie web.

En cuanto al tema de interactividad, al finalizar este trabajo de investigación se entiende que la estrategia de uso de enlaces en cada publicación no está funcionando de la manera más adecuada, porque el número de ingresos a YouTube por medio de esta plataforma no es relevante, considerando que gran parte de los entrevistados mencionaron que dan clic a los enlaces de manera esporádica. Para terminar, la presencia de Enchufe.tv en Facebook no es importante, ya que los usuarios analizados dijeron que les dan un mayor peso a los contenidos publicados directamente en YouTube que en otras redes sociales. Igualmente, la Like page no ha logrado crear una fidelización con los fans.

En resumen, los textos, imágenes y símbolos de las publicaciones en la Like page de la serie web evidencian que no existe una estrategia de comunicación que permita lograr los objetivos deseados por la marca. La falta de contexto, ya sea por el contenido de las imágenes o de los textos, en las publicaciones no permite que los mensajes lleguen de manera clara a los usuarios y no se cree un engagement completo que atraiga a los seguidores y los fidelice a los contenidos y a la marca en sí. En la Like page de Enchufe.tv se debería publicar contenidos que tengan contexto o que por lo menos brinden los elementos necesarios para entender el mensaje, como establece la fórmula propuesta por Merodio (2010, 5), de manera que se facilite al usuario el entendimiento del mismo.

En la Like page no existe fidelización porque los seguidores consideran que Enchufe.tv surgió como un producto repentino, que, si bien ha logrado permanecer en YouTube por varios años, no ha logrado dejar esa fama ocasional para plantarse como un producto con visión a futuro. El engagement que se produce en la Like page no es suficiente para hacer que los seguidores se mantengan pendientes de los contenidos. Durante casi seis años, Enchufe.tv no ha logrado tener una comunidad comprometida con su marca, pues fueron los mismos seguidores quienes manifestaron no sentirse como verdaderos fans de la serie. En esta investigación, no se registró una retroalimentación directa por parte de Enchufe.tv a los comentarios realizados por los usuarios. Si bien se puede dar una repuesta a los seguidores de manera interna, demostrar interés públicamente por las inquietudes 
de los fans, establecería una mejor cercanía con usuarios nuevos y antiguos. En el perfil de la serie web, se pudo observar que la capacidad dialógica prima en la comunidad, pues las personas dan a conocer sus criterios ante el tema que se presente.

\section{Referencias}

Acaso, María. 2006. El lenguaje visual. Barcelona: Paidós.

Barquet, Mercedes. 2002. “Reflexiones sobre teorías de género, hoy”. Umbrales 11: 9-38.

Crovi, Delia, María de los Ángeles López y Rocío López. 2009. Redes sociales: análisis y aplicaciones. Ciudad de México: Universiada Autónoma de México (UNAM)/Plaza y Valdés.

García. José María. 2002. "Virtualidad, realidad, comunidad. Un comentario sociológico sobre la semántica de las nuevas tecnologías digitales”. Papers, Revista de sociología (68): 81-106.

Marquina, Julián. 2013. Plan social media y community manager. Barcelona: Universitat Oberta de Catalunya (UOC).

Martínez, Josep, Jesús Sánchez y M. Concepción Parra. 2015. Marketing digital: guía básica para digitalizar tu empresa. Madrid: UOC.

Merodio, Juan. 2010. Marketing en redes sociales. Mensajes de empresa para gente selectiva. Madrid: Juan Merodio.

Montaño, María Victoria. 2015. Enchufe tv: estéticas de la cotidianidad y marcas del humor. Quito: UASB-E.

Nicolás Ojeda, Miguel Ángel y María del Mar Grandío (coord.). 2012. Estrategias de comunicación en redes sociales. Barcelona: Gedisa.

Rodríguez, Delia. 2000. Memecracia: Los virales que nos gobiernan. Barcelona: Gestión.

Whitaker, Reginald. 1999. El fin de la privacidad: cómo la vigilancia total se está convirtiendo en realidad. Barcelona: Paidós Ibérica 